\title{
Daniela Morgan
}

\section{Modulação da enzima NAD(P)H oxidase pela}

glicose, palmitato e interleucina - $1 \beta$ e sua participação no processo de secreção de insulina induzido pela glicose.

Tese de doutorado apresentada ao
Instituto de Ciências Biomédicas da
Universidade de São Paulo para a
obtenção do Título de Doutor em
Ciências (Fisiologia).




\section{RESUMO}

A expressão e ativação da enzima $\mathrm{NAD}(\mathrm{P}) \mathrm{H}$ oxidase em ilhotas pancreáticas foi descrita pela primeira vez, através de estudos realizados em nosso laboratório (OLIVEIRA, HR et al, 2003) que demonstraram a expressão gênica e proteíca da enzima nas células $B$, além da ativação da mesma mediada pela glicose. $O$ processo de secreção de insulina induzido pela glicose é acompanhado por aumento na geração de EROS e esse aumento é, pelo menos em parte, mediado pela ação da enzima $\mathrm{NAD}(\mathrm{P}) \mathrm{H}$ oxidase (semelhante a expressa em células fagocitárias). Neste projeto, demonstramos a modulação da enzima $\mathrm{NAD}(\mathrm{P}) \mathrm{H}$ oxidase pela glicose, palmitato e interleucina - $1 \beta$ através da análise da expressão protéica do componente $\mathrm{p} 47^{\mathrm{PHOX}}$ e pela atividade dessa enzima via produção de superóxido e peróxido de hidrogênio. Demonstramos também a participação da enzima $\mathrm{NAD}(\mathrm{P}) \mathrm{H}$ oxidase no processo de secreção de insulina induzido pela glicose pois a inibição da enzima pelo DPI e oligonucleotídeo anti p47 ${ }^{\text {PHOX }}$ promoveu uma diminuição da secreção do hormônio. Apartir desse dado passamos a avaliar o mecanismo de ação da enzima no processo secretório e demonstramos que a inibição dessa enzima promove uma inibição de genes essenciais no processo de secreção de insulina como GLUT-2 e Glicoquinase.

Assim podemos concluir que a enzima $\mathrm{NAD}(\mathrm{P}) \mathrm{H}$ oxidase é modulada pela glicose, palmitato e interleucina $1 \beta$ e que essa enzima participa do processo de secreção insulina modulando genes essenciais para o processo secretório como GLUT-2 e glicoquinase. 


\section{ABSTRACT}

The expression and activity of the componenents of $\mathrm{NAD}(\mathrm{P}) \mathrm{H}$ oxidase in pancreatic islets were described for the first time in our laboratory (OLIVEIRA, HR et al, 2003). It was shown the gene and protein expression of the components of this enzyme in Beta cells and that enzyme activation is mediated by glucose. Glucose induced insulin secretion was followed by increase in EROS generation and this increase was in part mediated by $\mathrm{NAD}(\mathrm{P}) \mathrm{H}$ oxidase activation (the same mechanism observed in phagocytes).

In this study, the modulation of $\mathrm{NAD}(\mathrm{P}) \mathrm{H}$ oxidase activity by glucose, palmitate and interleukin $1 \beta$ was investigated through protein expression of $\mathrm{p} 47^{\text {PHOX }}$ and activity of this enzyme through superoxide and hydrogen peroxide production. To determinate the role of $\mathrm{NAD}(\mathrm{P}) \mathrm{H}$ oxidase in the process of glucoseinduced insulin secretion the enzyme was inhibited by DPI and oligonucleotide anti $\mathrm{p} 47^{\text {PHOX }}$, in the both cases the enzyme inhibition produced a decrease on insulin secretion. In order to investigated $\mathrm{NAD}(\mathrm{P}) \mathrm{H}$ oxidase mechanism of action in insulin secretion, we shown that the inhibition enzyme by DPI reduced the GLUT-2 and glucokinase gene expression.

We can concluded hat $\mathrm{NAD}(\mathrm{P}) \mathrm{H}$ oxidase was modulated by glucose, palmitate and interleukin $1 \beta$ and that enzyme participed in process of glucoseinduced insulin secretion through modulation of GLUT-2 and glucokinase gene expression. 


\section{INTRODUÇÃO}

\subsection{Mecanismo de secreção de insulina induzido pela glicose}

Em condições fisiológicas, a manutenção da normoglicemia é garantida principalmente pela secreção de insulina, que promove a captação, o armazenamento e a rápida utilização da glicose por quase todos os tecidos do organismo, especialmente pelos músculos, tecido adiposo e fígado.

A secreção de insulina é estimulada por substratos energéticos metabolizáveis pela célula B pancreática, sendo a glicose o secretagogo mais importante. A glicose é transportada para o interior da célula B por uma proteína de membrana, denominada transportador de glicose tipo 2 (GLUT-2). Após entrar na célula $B$, a glicose é fosforilada à glicose-6-fosfato (G-6-P) pela Glicoquinase, que apresenta papel preponderante na fosforilação da glicose nas células $B$ (MATSCHINSKY FM, 1996). A Glicoquinase tem papel fundamental na regulação do fluxo glicolítico e, portanto, na secreção de insulina, o que caracteriza essa enzima como o sensor da glicose nas células secretoras de insulina. $O$ destino preferencial da G-6-P na célula B é a glicólise (BOSCHERO AC, 1996). O piruvato formado no citoplasma é transportado à mitocôndria, onde é convertido a acetilCoA pela piruvato desidrogenase $(\mathrm{PDH})$. Subseqüentemente, acetil-CoA entra no ciclo de Krebs levando a um aumento de nicotinamida adenina dinucleotídeo (NADH) e flavina adenina dinucleotídeo (FADH2). O metabolismo de glicose gera ATP e a relação ATP/ADP aumenta no citoplasma (MATSCHINSKY FM, 1996). 
Essa relação ATP/ADP aumentada resulta na inibição dos canais $K_{A T P}$ e na despolarização da célula. A despolarização da membrana celular resulta em abertura dos canais de cálcio sensíveis à voltagem (VDCC), ocorrendo influxo de $\mathrm{Ca}^{2+}$ e conseqüente aumento da concentração intracelular de $\mathrm{Ca}^{2+}$ e desencadeamento do processo exocitótico (PRENTKI M et al, 1996).

Outro efeito importante da glicose nas células B é o de desencadear a mobilização de cálcio pelas organelas celulares, graças à geração de segundos mensageiros intracelulares ativados pela metabolização intracelular da glicose. A estimulação das células B pela glicose leva à ativação de isoformas da fosfolipase C (PLC), promovendo a hidrólise de fosfolípides de membrana e gerando inositol 1-4-5-trifosfato $\left(\mathrm{IP}_{3}\right)$ e diacilglicerol (DAG). $\mathrm{O} \quad \mathrm{IP}_{3}$ ativa os canais de cálcio localizados na membrana do retículo endoplasmático com a saída de cálcio da organela e aumento da concentração desse íon no citosol. O DAG, por sua vez, também produz o mesmo efeito sobre a concentração de cálcio intracelular, ao ativar os canais de cálcio sensíveis à voltagem da membrana plasmática, permitindo a passagem do cátion do meio extracelular para o intracelular (SCHREY MP et al, 1983 e BEST L, 1984). O DAG também ativa a proteína cinase C (PKC) (PERSAUD SJ et al, 1992) que ativa proteínas dos grânulos secretórios de insulina que, juntamente com o Ca2+, promoverão a ativação do sistema de microtúbulos e microfilamentos, responsável pela translocação desses grânulos para as proximidades da membrana plasmática e conseqüente exocitose. Outra função proposta para a PKC é de ativação da adenilato ciclase (que 
também ocorre por outros mecanismos, durante a glicólise) com o conseqüente aumento do conteúdo intracelular de AMPc (HUGHES SJ et al, 1996).

Alguns metabólitos do ácido araquidônico ( $\mathrm{AA})$, liberados sob ação da fosfolipase $A_{2}\left(P L A_{2}\right)$, como as prostaglandinas $(P G)$ e leucotrienos, estão envolvidos com a regulação da secreção de insulina. As $P G$ do tipo $E\left(P G E_{1}\right.$ e $\mathrm{PGE}_{2}$ ) inibem a secreção de insulina estimulada pela glicose tanto in vitro como in vivo, enquanto que os leucotrienos estimulam a secreção de insulina. (TURK et al 1987. O aumento do cálcio, no citoplasma das células B, ativa proteínas cinases que interagem com componentes da maquinaria microtubular exocitótica resultando na mobilização e liberação dos grânulos de insulina) (figura 1).

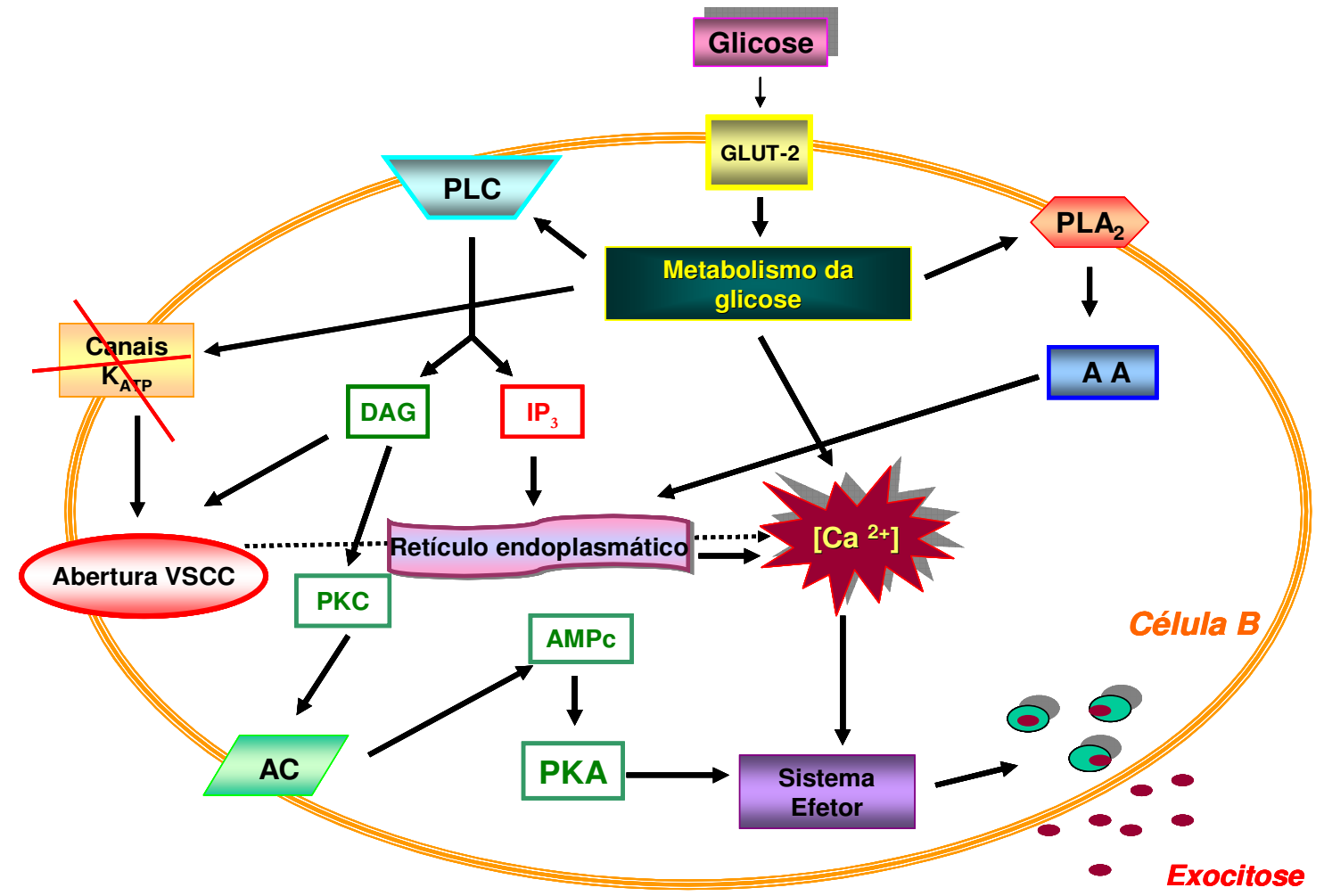

Figura 1. Esquema representativo da célula $B$ e os diversos componentes que geram sinais intracelulares responsáveis pelo processo da secreção de insulina. 


\subsection{Espécies Reativas de Oxigênio e a Secreção de Insulina}

As células B pancreáticas são extremamente susceptíveis ao estresse oxidativo devido à baixa expressão e atividade das enzimas antioxidantes que defendem as células dos agentes oxidantes (LENZEN et al. 1996). É sabido que as espécies reativas de oxigênio (EROS) alteram a função da célula $B$ causando a destruição dessas células. As EROS interferem com enzimas envolvidas no metabolismo da glicose (NAKAZAKI et al, 1995), inibem a síntese de ácido dexorribonucléico (DNA), e causam fragmentação do DNA, provavelmente através da ativação da poli (ADP - ribose) polimerase e diminuem o conteúdo de NAD+ (RADONS, et al. 1994). Muitos estudos têm demonstrado que o $\mathrm{H}_{2} \mathrm{O}_{2}$ interfere na atividade das enzimas da via glicolítica (BRODIE \& RED, et al. 1987) e na fosforilação oxidativa (ZHANG, Y et al, 1990).

Estudos propuseram que $\mathrm{o}_{2} \mathrm{O}_{2}$ inibe a secreção de insulina das ilhotas pancreáticas diminuindo a relação ATP/ADP, causando a abertura de canal de potássio sensível ao ATP (K $\left.\mathrm{K}_{\mathrm{ATP}}\right)$ e hiperpolarização da membrana. A hiperpolarização da membrana pode induzir o fechamento os VDCC dependente e então, reduzir a concentração de cálcio intracelular (DREWS, et al. 1998).

Por outro lado, estudos recentes demonstraram que o aumento da secreção de insulina de $3 \mathrm{mM}$ para $20 \mathrm{mM}$ de glicose é acompanhado por um aumento na formação de $\mathrm{H}_{2} \mathrm{O}_{2}$ e por uma diminuição da razão glutationa reduzida e glutationa oxidada (GSH/GSSH) na linhagem celular INS-I e nas ilhotas pancreáticas. Esse mesmo estudo demonstrou que baixas concentrações de $\mathrm{H}_{2} \mathrm{O}_{2}$ (1- $\left.4 \mu \mathrm{M}\right)$ na 
presença de $3 \mathrm{mM}$ de glicose promovem um aumento da secreção de insulina, e que em meio livre de cálcio, esse aumento na secreção de insulina provocado pelo $\mathrm{H}_{2} \mathrm{O}_{2}$ é inibido, demonstrando que $\circ \mathrm{H}_{2} \mathrm{O}_{2}$ promove secreção de insulina dependente do cálcio extracelular (JINGBO, P et al, 2007).

Diante dessas evidências torna-se claro que $\mathrm{o}_{2} \mathrm{O}_{2}$ e outros tipos de EROs são potentes sinalizadores para a secreção de insulina em resposta ao aumento da glicose.

\subsection{Espécies Reativas de Oxigênio e as vias de sinalização}

Originalmente as espécies reativas de oxigênio (EROs) foram reconhecidas como instrumento de defesa, caracterizadas por causar um burst respiratório em neutrófilos. No entanto, recentes estudos têm demonstrado um novo papel para as EROs, como a participação nas vias de sinalização intracelular (HANCOCK, J.T., et al, 2001).

Estímulos extracelulares transmitem sinal através de uma variedade de vias de sinalização, incluindo sinalização de moléculas como as proteínas tirosina cinases (PTKs), serina/treonina cinases, fosfolipases e cálcio. Quando as células são estimuladas pelas EROs, sinais são transferidos pelas mesmas vias de sinalização desencadeada por outros fatores de crescimento. Agentes oxidantes (espécies reativas de oxigênio radicalares e não radicalares) ativam PTKs e componentes da via de sinalização incluindo as proteínas cinases ativadora da mitogênse (MAP cinases), PKC, fosfolipase $\mathrm{C} \gamma(\mathrm{PKC} \gamma)$ e cálcio $\left(\mathrm{Ca}^{2+}\right)$. Podem 
também regular moléculas envolvidas na sinalização intracelular, as EROs também regulam fatores de transcrição como: $c$-fos, $c$-jun, c-myc, fator nuclear $\kappa \mathrm{B}$ (NF-кB) e o ativador da proteína -1 (AP-1) (KAMATA, et al, 1999).

A fosforilação de proteínas apresenta um importante papel na sinalização intracelular. Proteínas, enzimas, receptores e fatores de transcrição são ativados e inativados pelo estado de fosforilação de específicos resíduos de aminoácidos. 0 estado de fosforilação é ditado pela atividade de duas classes de enzima: as proteínas cinases e as proteínas fosfatases (SUZUKI YJ, et al, 1996).

Estudos demonstraram que as MAP cinases são ativadas pelo peróxido de hidrogênio $\left(\mathrm{H}_{2} \mathrm{O}_{2}\right)$, podendo causar a modulação da expressão de genes (HANCOCK, J.T., et al, 2001). $\mathrm{O} \mathrm{H}_{2} \mathrm{O}_{2}$ pode também inibir fosfatases, provavelmente pela oxidação direta do sitio ativo de cisteína dessas enzimas. A via da Janus Cinase/ transdutores de sinais e ativadores da transcrição (JAK/STAT) também é ativada pelo $\mathrm{H}_{2} \mathrm{O}_{2}$ (SIMON, et al.1998), sugerindo que o $\mathrm{H}_{2} \mathrm{O}_{2}$ pode ser um transmissor de mensagens para o núcleo da célula através das duas últimas vias de transdução (fosforilação de proteínas e inibição de fosfatases) (HANCOCK, J.T., et al, 2001). Em adipócitos, $\mathrm{o}_{2} \mathrm{O}_{2}$ inibe a atividade da proteína tirosina fosfatase (PTPase) denominada PTP1B a qual se associa ao receptor de insulina (IR), defosforilando-o. Assim a inibição dessa enzima causa aumento da fosforilação do receptor de insulina (IR), aumento da ativação do fosfatidilinositol 3 - cinase (PI3K) e subseqüentemente aumenta a ativação da proteina cinase B (AkT/PKB), levando ao aumento da translocação de GLUT-4 
para membrana em resposta à insulina com aumento da captação de glicose (MAHADEV, et al. 2001).

A PKC é regulada pelo estado redox da célula. Esta enzima também é ativada pelo diacilglicerol (DAG) ou pelo forbol 12-miristato 13 acetato (PMA) sendo regulada por várias vias, como: fosforilação em tirosina, oxidação de lipídeos e concentração de cálcio. Recentemente, demonstrou que o $\mathrm{H}_{2} \mathrm{O}_{2}$ induz a fosforilação em tirosina da PKC, e essa fosforilação aumenta a atividade dessa enzima (KAMATA, et al, 1999).

$\mathrm{O} \mathrm{H}_{2} \mathrm{O}_{2}$ induz a fosforilação em tirosina da fosfolipase $\mathrm{C}(\mathrm{PLC} \gamma)$ que por sua vez produz inositol 1,4,5- trifosfato $\left(\mathrm{IP}_{3}\right)$, o qual mobiliza cálcio a partir de compartimentos intracelulares para o citossol. $\mathrm{O} \mathrm{IP}_{3}$ gerado pela PLC $\gamma$ liga-se ao receptor $\mathrm{IP}_{3} / \mathrm{Ca}^{2+}$ no reticulo endoplasmático elevando o cálcio intracelular. (KAMATA, et al, 1999).

Assim as EROs aumentam a concentração do cálcio intracelular $\left[\mathrm{Ca}^{+2}\right]_{\mathrm{i}}$ com a produção de inositois fosfatos. $\mathrm{O}$ aumento do $\left[\mathrm{Ca}^{+2}\right]_{i}$ na célula é resultado da somatória do influxo do $\mathrm{Ca}^{+2}$ extracelular com o remanejamento do $\mathrm{Ca}^{+2}$ dos estoques intracelulares (DREWS, et al, 1999). 


\subsection{NADPH oxidase}

\subsubsection{Estrutura e ativação}

A $\mathrm{NAD}(\mathrm{P}) \mathrm{H}$ oxidase consiste em um complexo enzimático formado pelo agrupamento de diferentes componentes citoplasmáticos e de membrana associados. Esse complexo enzimático pode ser encontrado em diversas células de origem mesodermal e tem como substrato as coenzimas NADH (nicotinamida adenina dinucleotídeo reduzida) ou NADPH (nicotinamida adenina dinucleotídeo fosfato). A isoforma mais estudada é a $N A D(P) H$ oxidase leucocitária. Essa enzima é encontrada em células fagocitárias (neutrófilos e macrófagos) e em linfócitos B e caracteriza-se por provocar um aumento transitório do consumo de oxigênio, fenômeno este denominado de burst respiratório (BABIOR, 1999).

A NAD $(\mathrm{P}) \mathrm{H}$ oxidase leucocitária atua como uma cadeia de transporte de elétrons, tendo como aceptor final desses elétrons o oxigênio molecular $\left(\mathrm{O}_{2}\right)$. A enzima catalisa a produção de ânions superóxidos $\left(\mathrm{O}_{2}{ }^{\circ-}\right)$ através da redução da molécula de oxigênio (doação de 1 elétron $e^{-}$) e utiliza como doador de elétrons, predominantemente, uma molécula de $\mathrm{NADPH}(1)$. Os radicais $\mathrm{O}_{2}{ }^{\bullet-}$ gerados são liberados no interior de fagócitos durante a fagocitose e devido a sua toxicidade (alta reatividade) promovem facilmente à destruição de bactérias e outros microrganismos invasores. Os radicais $\mathrm{O}_{2}{ }^{--}$são convertidos em $\mathrm{H}_{2} \mathrm{O}_{2}$ espontaneamente ou em reação de dismutação catalisada pela superóxido dismutase (SOD) (2). A interação entre $\mathrm{H}_{2} \mathrm{O}_{2} \mathrm{e} \mathrm{O}_{2}{ }^{\bullet-}$ conduz à formação do radical 
hidroxil $\mathrm{OH}^{\bullet}$ (3). Juntamente com o $\mathrm{O}_{2}{ }^{\circ}$, $\mathrm{o} \mathrm{OH}^{\bullet}$ e o $\mathrm{H}_{2} \mathrm{O}_{2}$ também contribuem para a eliminação de bactérias e de outros agentes invasores (JONES et al., 2000).

\section{Esquema da reação}

\section{NADPH oxidase}

$$
\begin{array}{ll}
\mathrm{NADPH}+\mathrm{O}_{2} \longrightarrow \mathrm{NADP}^{+}+\mathrm{O}_{2}^{\circ-}+2 \mathrm{H}^{+} \\
2 \mathrm{O}_{2}^{\circ-}+2 \mathrm{H}^{+} \longrightarrow & \mathrm{H}_{2} \mathrm{O}_{2}+\mathrm{O}_{2} \\
\mathrm{O}_{2}^{\circ-}+\mathrm{H}_{2} \mathrm{O}_{2}+\mathrm{H}^{+} \longrightarrow \mathrm{O}_{2}+\mathrm{H}_{2} \mathrm{O}+\mathrm{OH}^{\bullet}
\end{array}
$$

A NAD $(\mathrm{P}) \mathrm{H}$ oxidase é formada basicamente por 5 componentes: $\mathrm{p} 40^{\text {PHOX }}$, $\mathrm{p} 47^{\text {PHOX }}, \mathrm{p} 67^{\text {PHOX }}, \mathrm{p} 22^{\text {PHOX }}$ e gp91 ${ }^{\text {PHOX }}$ (a terminação $\mathrm{PHOX}$ refere-se à "Phagocyte Oxidase"). Nas células fagocitárias em repouso (não ativadas), três destes componentes, $\mathrm{p} 40^{\text {PHOX }}$, $\mathrm{p} 47^{\text {PHOX }}$ e $\mathrm{p} 67^{\text {PHOX }}$ encontram-se no citoplasma formando um complexo. Os outros dois componentes - p22 $2^{\text {PHOX }}$ e gp91 ${ }^{\text {PHOX }}$ encontram-se localizados nas membranas de vesículas secretoras e grânulos específicos citoplasmáticos, formando uma flavohemeproteína heterodimérica conhecida como citocromo b558. A separação desses dois grupos de componentes em compartimentos sub-celulares distintos garante que a oxidase encontre-se inativa nas células em repouso.

A ativação do complexo $\mathrm{NAD}(\mathrm{P}) \mathrm{H}$ oxidase requer o envolvimento de, pelo menos, duas proteínas G. No estado inativo, essas proteínas encontram-se ligadas a guanosina difosfato (GDP); entretanto, quando a célula é estimulada ocorre à ativação do sistema e a substituição de GDP por GTP (guanosina trifosfato). Essas proteínas G são denominadas: Rac2, que no estado inativo 
encontra-se no citoplasma formando um complexo dimérico com Rho-GDI (inibidor da dissociação do GDP) e Rap1A, localizada na membrana associada ao citocromo b558. Durante a ativação, Rac2 liga-se ao GTP e migram para a membrana celular, juntamente com os demais componentes citoplasmáticos. Simultaneamente, o citocromo b558 e Rap1A são conduzidos à superfície celular através da migração e fusão de vesículas secretoras e grânulos específicos com a membrana plasmática.

Quando a célula fagocitária (neutrófilos, macrófagos) é ativada, o componente $\mathrm{p} 47^{\text {PHOX }}$ é fosforilado e todo o complexo citoplasmático migra para a membrana na qual se associa ao citocromo b558 promovendo desta forma a ativação da enzima. Alguns estudos sugerem que a migração do complexo citoplasmático para a membrana seja importante na indução de uma conformação correta da flavohemeproteína (citocromo b558), garantindo a perfeita ligação do substrato (NADPH) e o fluxo de elétrons através do complexo (BABIOR \& LAMBETH, 2002).

A fosforilação do componete $p 47^{P H O X}$ é uma etapa essencial na ativação da $\mathrm{NAD}(\mathrm{P}) \mathrm{H}$ oxidase. Inicialmente, acreditava-se que o componente $\mathrm{p} 47^{\mathrm{PHOX}}$ fosse $\mathrm{o}$ único sítio de fosforilação para ativação da enzima. Entretanto, recentemente foram identificados sítios de fosforilação em outros componentes, tais como, p67 ${ }^{\text {PHOX }}$, p40 ${ }^{\text {PHOX }}$, e nos componentes de membrana - citocromo b558 (FUCHS et al., 1997).

A fosforilação do componente $\mathrm{p} 47^{\text {PHOX }}$ ainda é a mais estudada. Esse componente é fosforilado, principalmente, em resíduos de serina. O PMA, $12-$ 
miristato-13-acetato de forbol, é um importante ativador do sistema NAD(P)H oxidase e essa ativação ocorre por mecanismo independente de receptor e de forma indireta por estimulação da PKC (BABIOR, 1999). A atividade da enzima $\mathrm{NAD}(\mathrm{P}) \mathrm{H}$ oxidase pode ser inibida, in vitro, por difenilenoiodônio (DPI) que, assim como o PMA, é uma importante ferramenta no estudo desta enzima.

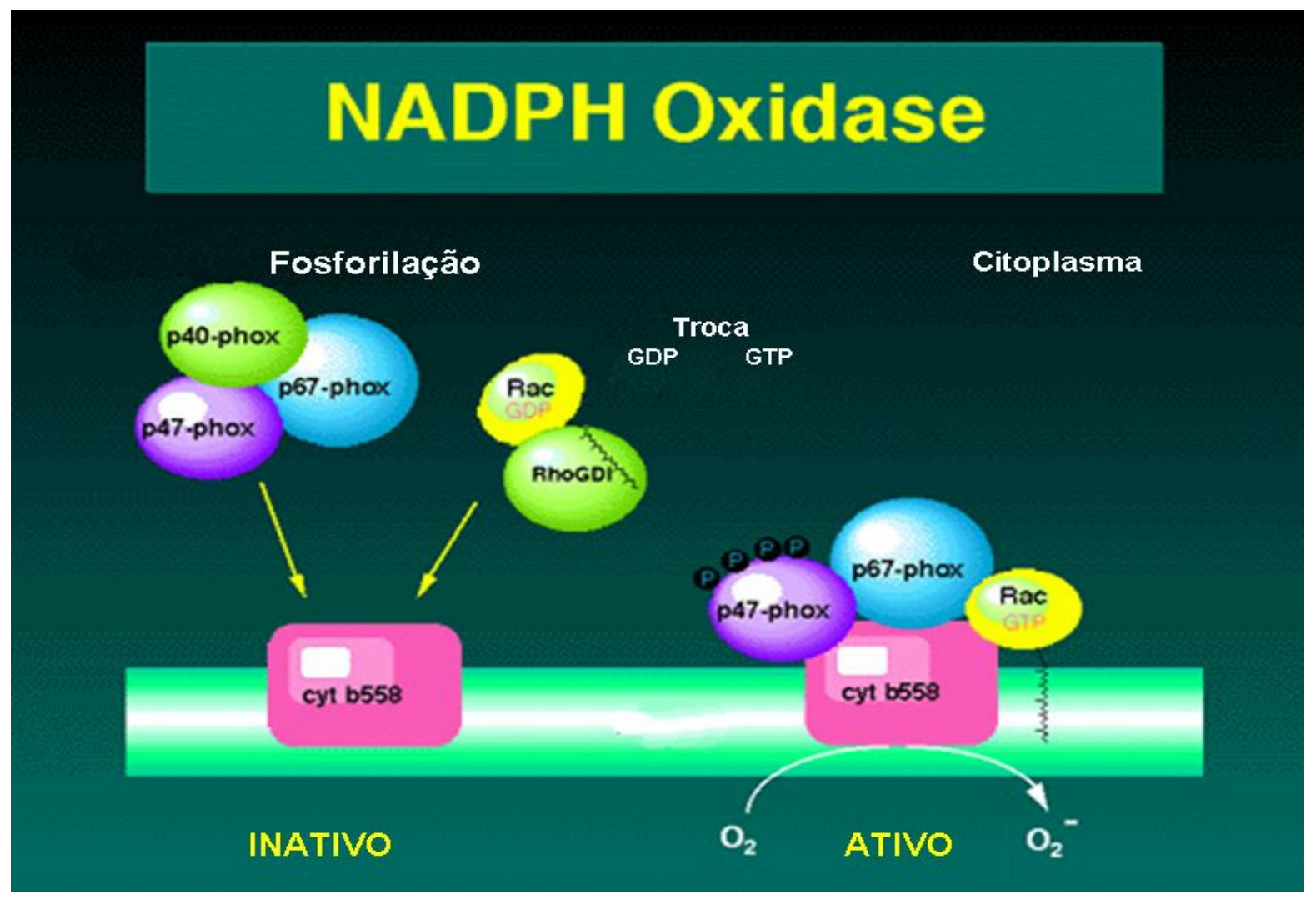

Figura 2. Esquema representativo da enzima $N A D(P) H$ oxidase e sua ativação. Os números indicam o peso molecular em $\mathrm{kDa}$ dos vários componentes. A ativação da enzima depende da fosforilação do componente citoplasmático p47phox que ao ser fosforilado migra para a membrana onde se combina com flavocitocromo b558 tornando o complexo de NADPH-oxidase ativo. 
Atualmente, o interesse no estudo da $\mathrm{NAD}(\mathrm{P}) \mathrm{H}$ oxidase tem aumentado devido à identificação dessa enzima em várias células não-fagocitárias. Apesar de, classicamente, a $\mathrm{NAD}(\mathrm{P}) \mathrm{H}$ oxidase ser considerada uma enzima-chave no mecanismo antipatogênico de células fagocitárias, vários estudos têm demonstrado a presença de NADPH oxidase-like, ou seja, de oxidases similares à oxidase fagocitária em diversas populações celulares, tais como: fibroblastos (PAGANO et al., 1995), células musculares lisas e células endoteliais (ZAFARI et al., 1998) e ilhotas pancreáticas (Oliveira, HR etal, 2003).

Estudos desenvolvidos em nosso laboratório demonstram, pela primeira vez, a expressão e a atividade da enzima $\mathrm{NAD}(\mathrm{P}) \mathrm{H}$ oxidase em ilhotas pancreáticas. Esse estudo demonstrou a expressão gênica do componente gp91 ${ }^{\text {PHOX }}, \mathrm{p} 22^{\text {PHOX }}$ e $\mathrm{p} 47^{\text {PHOX }}$ por RT-PCR e a expressão protéica do componente p67 $7^{\text {PHOX }}$ e p47 $7^{\text {PHOX }}$ por Western Blotting. Também demonstramos por Imunohistoquímica, que a enzima $\mathrm{NAD}(\mathrm{P}) \mathrm{H}$ oxidase era expressa predominantemente nas células $B$ secretoras de insulina e que a enzima NAD $(P) H$ oxidase é ativada por $5.6 \mathrm{mM}$ de glicose e que essa ativação é em parte mediada pela PKC (Oliveira, HR etal al 2003).

Uchizono, Y eta al, 2007 demonstrou que ilhotas isoladas de ratos expressam os RNAm dos componentes da NAD(P)H oxidase, Nox1, Nox2 (gp91 ${ }^{\text {PHOX }}$ ), Nox4 e p22phox componentes de membrana associados e p47phox, Noxo1 (homologo do p47phox), Noxa1 (homologo do p67phox) e p40phox componentes citossólicos. O estudo demonstrou também por imunohistoquímica 
que a expressão do componente $\mathrm{p} 47^{P H O X}$ está predominantemente nas células $\mathrm{B}$, comprovando dados obtidos em nosso laboratório.

\subsubsection{Modulação da enzima NAD(P)H oxidase}

A atividade e expressão da enzima $\mathrm{NAD}(\mathrm{P}) \mathrm{H}$ oxidase pode ser regulada por vários metabólitos, tais como a glicose, aminoácidos, ácidos graxos e citocinas. A glicose é o principal substrato utilizado pelos neutrófilos. Este substrato é oxidado na glicólise e na via das pentoses. NADPH gerado através da ação das enzimas glicose-6-fosfato desidrogenase e 6-fosfogliconato desidrogenase, é o principal substrato da $N A D(P) H$ oxidase em fagócitos. GARCIA et al. (1999) verificaram que a glutamina, assim como a glicose, também é significativamente consumida pelos neutrófilos. A metabolização deste aminoácido fornece ATP e NADPH, que é utilizado como substrato pela enzima $\mathrm{NAD}(\mathrm{P}) \mathrm{H}$ oxidase. Além de aumentar a oferta de NADPH, a glutamina também estimula, em neutrófilos, a expressão de alguns componentes da $\mathrm{NAD}(\mathrm{P}) \mathrm{H}$ oxidase (gp91 ${ }^{\text {PHOX }}$, p22 $2^{\text {PHOX }}$ e $\mathrm{p} 47^{\text {PHOX }}$ ) (PITHON-CURI et al., 2002). Os ácidos graxos, assim como a glutamina, também exercem importante ação na ativação da NAD(P)H oxidase (CHERNY et al., 2001; SHIOSE \& SUMIMOTO, 2000). Recente estudo mostrou que dietas ricas em ácidos graxos modulam a produção de superóxido por neutrófilos (LOPES et al., 1999). Em células vasculares, a atividade da enzima $\mathrm{NAD}(\mathrm{P}) \mathrm{H}$ oxidase (NOX) dependente de PKC é regulada por alta glicose e palmitato (INOGUCHI et al., 2000). 
Em células leucocitárias, as citocinas exercem importante efeito na expressão e na atividade da enzima NADPH oxidase. A atividade da NAD(P)H oxidase é modulada, em células leucocitárias, por citocinas que aumentam (TNF$\alpha$, IFN- $\gamma$ e IL-15) (NATHAN et al., 1983) ou diminuem (IL-4, IL-10 e IL-13) (ABRAMSON et al., 1990; SOZZANI et al., 1995) a produção de superóxido. CASSATELLA et al., 1991, em estudos com monócitos humanos demonstraram que o TNF- $\alpha$ aumenta a expressão da $p 47^{\mathrm{PHOX}}$ e que o IFN- $\gamma$, além de aumentar a expressão da $\mathrm{p} 47^{\mathrm{PHOX}}$ (efeito semelhante ao TNF- $\alpha$ ), também estimula a expressão das subunidades de membrana- gp91 ${ }^{\mathrm{PHOX}}$ e $\mathrm{p} 22^{\mathrm{PHOX}}$. Os efeitos das citocinas na regulação da expressão e da atividade da NADPH oxidase em células leucocitárias nos alerta para o fato de que a ativação da $N A D(P) H$ oxidase possa estar envolvida no mecanismo de destruição (apoptose/necrose) verificada após a exposição crônica das ilhotas pancreáticas a diferentes citocinas e, portanto, possa estar relacionada com a patogênese do Diabetes mellitus tipo 1.

Altas concentrações de glicose e ácidos graxos (particularmente, ácido palmítico) também estimulam a atividade da enzima $\mathrm{NAD}(\mathrm{P}) \mathrm{H}$ oxidase em células endoteliais e musculares lisas em cultura, sendo esta ativação dependente de PKC (INOGUCHI et al.,2000).

Este projeto, teve como objetivo avaliar os efeitos da glicose, do palmitato e da interleucina $1 \beta(\mathrm{IL}-1 \beta)$ na regulação proteíca do componente $\mathrm{p} 47^{\mathrm{PHOX}}$ e na ativação da enzima através da mensuração da produção de superóxido. Assim como avaliar a participação da enzima $\mathrm{NAD}(\mathrm{P}) \mathrm{H}$ oxidase na produção de $\mathrm{H}_{2} \mathrm{O}_{2}$ e no processo de secreção de insulina através de estudos com bloqueadores do 
componente $\mathrm{p} 47^{\mathrm{PHOX}}$. Os dados obtidos visam o melhor entendimento do possível papel fisiológico da enzima $\mathrm{NAD}(\mathrm{P}) \mathrm{H}$ oxidase em ilhotas pancreáticas.

\section{DISCUSSÃO}

As espécies reativas de oxigênio (EROS), assim como o superóxido $\left(\mathrm{O}_{2}{ }^{*-}\right)$, o peróxido de hidrogênio $\left(\mathrm{H}_{2} \mathrm{O}_{2}\right)$ e radical hidroxil $\left(\mathrm{OH}^{\bullet}\right)$ são gerados nas células por várias vias através de processos bioquímicos como: redução parcial do oxigênio molecular durante o transporte de elétrons na cadeia respiratória, oxidação de catecolaminas, ativação da cascata do ácido araquidônico, ativação do sistema xantina-xantina oxidase ou durante a metabolização de xenobióticos no fígado pelo citocromo P450 ou pela ativação do óxido nítrico sintase (NOS) no endotélio vascular. As evidências indicam que o estado redox exerce um papel essencial não apenas na sobrevivência das células, mas também no sistema de sinalização celular (regulação redox) (KAMATA, et al, 1999).

Dados recentes do nosso laboratório demonstraram que células B das ilhotas pancreáticas expressam vários componentes da enzima $\mathrm{NAD}(\mathrm{P}) \mathrm{H}$ oxidase $\left(p 22^{\mathrm{PHOX}}, \mathrm{gp91}^{\mathrm{PHOX}}, \mathrm{p} 47^{\mathrm{PHOX}}\right.$ e $\mathrm{p} 67^{\mathrm{PHOX}}$ ) (OLIVEIRA, HR et al 2003) e que grande parte da produção $\mathrm{O}_{2}{ }^{*-}$ na célula $\mathrm{B}$ é devida à ativação dessa enzima (MORGAN, D et al 2007).

A proposta do presente projeto foi avaliar qual papel fisiológico e/ou patológico da enzima $\mathrm{NAD}(\mathrm{P}) \mathrm{H}$ oxidase, presente nas células $\mathrm{B}$ das ilhotas pancreáticas e como ocorre a sua regulação. 
Nossos resultados demonstraram que glicose modula a enzima $\mathrm{NAD}(\mathrm{P}) \mathrm{H}$ oxidase, promovendo um aumento na expressão do componente p47 $7^{\text {PHOX }}$ após 1 e 24 horas de incubação, e esse aumento de expressão é acompanhado do aumento da atividade da enzima verificada pela produção de superóxido. Foi demonstrado também que, similar aos leucócitos e células vasculares, a glicose estimula a formação de EROs principalmente via $N A D(P) H$ oxidase, uma vez que a produção de $\mathrm{O}_{2}{ }^{\circ}$ - é inibida na presença de DPI e do oligonucleotídeo anti$\mathrm{p} 47^{\mathrm{PHOX}}$ onde a expressão protéica do componente citoplasmático $\mathrm{p} 47^{\mathrm{PHOX}}$ foi inibida em aproximadamente 50-60\%. Esses resultados comprovam a participação da enzima $\mathrm{NAD}(\mathrm{P}) \mathrm{H}$ oxidase na produção de superóxido em ilhotas pancreáticas.

Os experimentos realizados com palmitato e IL-1B sobre a modulação da enzima $\mathrm{NAD}(\mathrm{P}) \mathrm{H}$ oxidase nas ilhotas pancreáticas, demonstraram que o conteúdo protéico do componente $\mathrm{p} 47^{\mathrm{PHOX}}$ aumenta na presença de glicose $5.6 \mathrm{mM}$ acrescido de palmitato e IL-1B após 1 hora de incubação. No entanto após 24 horas de incubação a glicose ainda promove o aumento da expressão da p47 PHOX, o que não acontece com o palmitato e com a IL-1B que promovem a diminuição $\mathrm{p} 47^{\mathrm{PHOX}}$. Diante desses resultados passamos a avaliar a atividade da enzima na presença do palmitato e da IL-1B e verificamos que q atividade da enzima $\mathrm{NAD}(\mathrm{P}) \mathrm{H}$ oxidase na presença de palmitato e IL-1B, aumenta após 1 hora de incubação e após 24 horas houve uma redução da produção das EROs .

Sabe-se que a IL-1B é conhecida por induzir apoptose através da ativação das caspases e conseqüente fragmentação do DNA. A IL-1B promove também um aumento na produção de óxido nítrico que interage com o superóxido levando a 
formação de peróxinitrito ('ONOO), um potente indutor de apoptose em ilhotas pancreáticas. O palmitato é um importante modulador da secreção de insulina induzida pela glicose, entretanto, a exposição crônica a este ácido graxo leva à lipotoxicidade das células B das ilhotas pancreáticas (ROBERTSON et al., 2004).

Diante dessas evidências, realizamos experimentos de viabilidade celular e de fragmentação de DNA após cultura das ilhotas pancreáticas na presença de $5.6 \mathrm{mM}$ de glicose acrescida de palmitato e IL-1B com o intuito de verificar uma possível ação apoptótica da IL-1B e do palmitato nas ilhotas pancreáticas. Nossos resultados demonstraram que tanto a $\mathrm{IL}-1 \mathrm{~B}$ quanto o palmitato não causaram apoptose .

Estudos recentes demonstraram que ilhotas pancreáticas incubadas por 24 horas na presença de alta concentração de glicose $(24.4 \mathrm{mM})$ acrescida de um coquetel de citocinas contendo: interleucina-1-beta (IL-1B), fator de necrose tumoral (TNF- $\alpha$ ) e interferon (IFN- $\gamma$ ) induzem à apoptose. O mesmo não ocorre na presença de baixa concentração de glicose $(5.5 \mathrm{mM})$. O efeito apoptótico só foi observado quando as três citocinas citadas são incubadas juntas. A IL-1B isoladamente não induz apoptose em qualquer (5.6 ou $24.4 \mathrm{Mm}$ ) concentração de glicose (GIL-MELLADO, JM et al, 2005). Esses estudos demonstraram também que, ilhotas pancreáticas incubadas em 2, 5.5, 11.1, 24.4 e 33.3mM de glicose por 48 horas tiveram aumento da ocorrência apoptose apenas na exposição crônica a alta glicose (33.3mM) e baixa glicose (2mM) (GIL-MELLADO, JM et al, 2005).

PIRO, S et al, 2002, demonstrou que ilhotas pancreáticas incubadas em presença de $16.7 \mathrm{mM}$ de glicose promovem aumento de apoptose apenas após 2 
dias de incubação e esse aumento de células em apoptose torna-se mais evidente após 3 dias de incubação. A fragmentação de DNA foi observada após 3 dias de cultura. Foi demonstrado também que ilhotas pancreáticas cultivadas em alta concentração de ácidos graxos livres $(2 \mathrm{mmol} / \mathrm{L})$ e alta glicose $(16.7 \mathrm{mM})$ tiveram aumento de apoptose após 2 dias de cultura e essa porcentagem torna-se mais evidente após 5-7 dias de cultura.

Na realidade, a redução do componente $\mathrm{p} 47^{\mathrm{PHOX}}$ e da produção das EROs, após 24 horas de incubação, podem ter papel importante no processo de proteção da integridade celular.

Assim, há fortes evidências de que a expressão e a atividade $N A D(P) H$ oxidase é regulada pela variação da concentração de glicose à qual as células $B$ são submetidas. Além do mais, estudos recentes demonstraram a participação importante do $\mathrm{H}_{2} \mathrm{O}_{2}$ na secreção de insulina induzida pela glicose (JINGBO, P et al, 2007). Diante desses fatos, decidimos estudar uma possível participação das EROs, produzidas via $\mathrm{NAD}(\mathrm{P}) \mathrm{H}$ oxidase, na secreção de insulina induzida pela glicose.

Para investigar a possível participação da $\mathrm{NAD}(\mathrm{P}) \mathrm{H}$ oxidase no processo de secreção de insulina, passamos a avaliar o efeito da inibição dessa enzima na secreção de insulina.

Após a incubação das ilhotas em concentrações crescentes de glicose na presença e na ausência de DPI, observamos diminuição da secreção estática de insulina na presença de 11.1 e $16.7 \mathrm{mM}$ de glicose. Com o intuito de confirmar esses resultados, realizamos experimentos com ilhotas perfundidas analisando 
minuto a minuto o comportamento secretório das células B. Nos experimentos de perfusão, na presença de DPI verificamos diminuição da secreção de insulina quando a concentração de glicose era elevada de 2.8 para $16.7 \mathrm{mM}$.

Considerando que o DPI é um inibidor farmacológico, optamos por confirmar esses dados utilizando o oligonucleotídeo antisense para $\mathrm{p} 47^{\mathrm{PHOX}}$, que também promoveu diminuição da secreção de insulina quando a concentração de glicose era elevada de 2.8 para $16.7 \mathrm{mM}$. Esses dados sugerem claramente um possível papel fisiológico da $\mathrm{NAD}(\mathrm{P}) \mathrm{H}$ oxidase na secreção de insulina induzida pela glicose.

Levando em conta que ilhotas isoladas expostas a baixas concentrações de $\mathrm{H}_{2} \mathrm{O}_{2}(1-4 \mu \mathrm{M})$, na presença de $3 \mathrm{mM}$ de glicose, promovem aumentam a secreção de insulina (JINGBO, P et al, 2007), passamos a avaliar a participação da enzima $\mathrm{NAD}(\mathrm{P}) \mathrm{H}$ oxidase na produção de peróxido de hidrogênio.

Nossos resultados demonstraram uma inibição na produção de $\mathrm{H}_{2} \mathrm{O}_{2}$ tanto na presença do DPI (inibidor farmacológico da enzima) e quanto na presença do oligonucleotídeo anitsense para p47 $7^{\mathrm{PHOX}}$

Assim podemos concluir que as EROs produzidas via $\mathrm{NAD}(\mathrm{P}) \mathrm{H}$ oxidase são importantes sinalizadores intracelulares no processo de secreção de insulina induzido pela glicose. Diante desse fato, passamos a avaliar qual mecanismo de ação das $E R O$ s produzidas via $\mathrm{NAD}(\mathrm{P}) \mathrm{H}$ oxidase na secreção de insulina.

A primeira hipótese do mecanismo de ação da enzima $\mathrm{NAD}(\mathrm{P}) \mathrm{H}$ oxidase, seria através da regulação de genes essenciais para o processo de secreção de insulina tais como: o transportador de glicose tipo 2 (GLUT-2), glicoquinase (GCK) 
e a pró-insulina. Assim, avaliamos a expressão gênica da glicoquinase, GLUT-2 e pró-insulina após 1 hora de incubação na presença do DPI. Nossos dados demonstraram diminuição na expressão gênica da glicoquinase e do GLUT-2 na presença de $16.7 \mathrm{mM}$ de glicose e de $10 \mu \mathrm{M}$ de DPI. Já a expressão gênica da próinsulina não alterou na presença do DPI.

Com esses dados podemos concluir que a enzima $\mathrm{NAD}(\mathrm{P}) \mathrm{H}$ oxidase participa do processo de secreção de insulina gerando EROs que agem como sinalizadores intracelulares regulando genes essenciais ao processo secretório como a glicoquinase e GLUT-2. Nossos dados mostram que a ação da enzima $\mathrm{NAD}(\mathrm{P}) \mathrm{H}$ oxidase se dá modulando o processo secretório e não na biossíntese da insulina uma vez que não tivemos alteração na expressão gênica da pró-insulina.

Uma segunda hipótese de ação dessa enzima seria através do remanejamento de cálcio intracelular uma vez que estudo recente demonstrou que ilhotas pancreáticas expostas à baixas concentrações de $\mathrm{H}_{2} \mathrm{O}_{2}(1.0-4.0 \mu \mathrm{M})$ na presença de $3.0 \mathrm{mM}$ de glicose aumentam a secreção de insulina. Este efeito é parcialmente abolido em meio livre de cálcio, mostrando que $\circ \mathrm{H}_{2} \mathrm{O}_{2}$ promove secreção de insulina dependente da entrada de $\mathrm{Ca}^{+2}$ extracelular (JINGBO, P et al, 2007). Por outro lado $\circ \mathrm{H}_{2} \mathrm{O}_{2}$ induz à fosforilação em tirosina da $\mathrm{PLC} \gamma$ nas células HL60, produzindo $\mathrm{IP}_{3}$, o qual se liga ao receptor $\mathrm{IP} 3 / \mathrm{Ca}^{2+}$ no retículo endoplasmático elevando o cálcio intracelular (KAMATA, et al, 1999). Além disso, a atividade do canal $\mathrm{Ca}^{2+} / \mathrm{ATP}$ ase e a do trocador $\mathrm{Na}+-\mathrm{Ca}^{2+}$ são modulados pelo estado redox da célula regulando os níveis de $\mathrm{Ca}^{2+}$ intracelular. 
Desta forma, nas células $\mathrm{B}, \circ \mathrm{H}_{2} \mathrm{O}_{2}$ pode agir aumentando o $\left[\mathrm{Ca}^{+2}\right]_{i}$ por dois mecanismos, aumento da liberação do $\mathrm{Ca}^{2+}$ dos estoques intracelulares e pelo aumento do influxo do $\mathrm{Ca}^{2+}$ através da membrana plasmática por ativação do canal de $\mathrm{Ca}^{2+}$ tipo L (NAKAZAKI, et al, 2000).

Em resumo, podemos afirmar que a manutenção de uma concentração basal de espécies reativas de oxigênio é necessária para a resposta secretória da secreção de insulina induzida pela glicose a qual é mantida, pelo menos em parte, pela ativação $\mathrm{NAD}(\mathrm{P}) \mathrm{H}$ oxidase. 


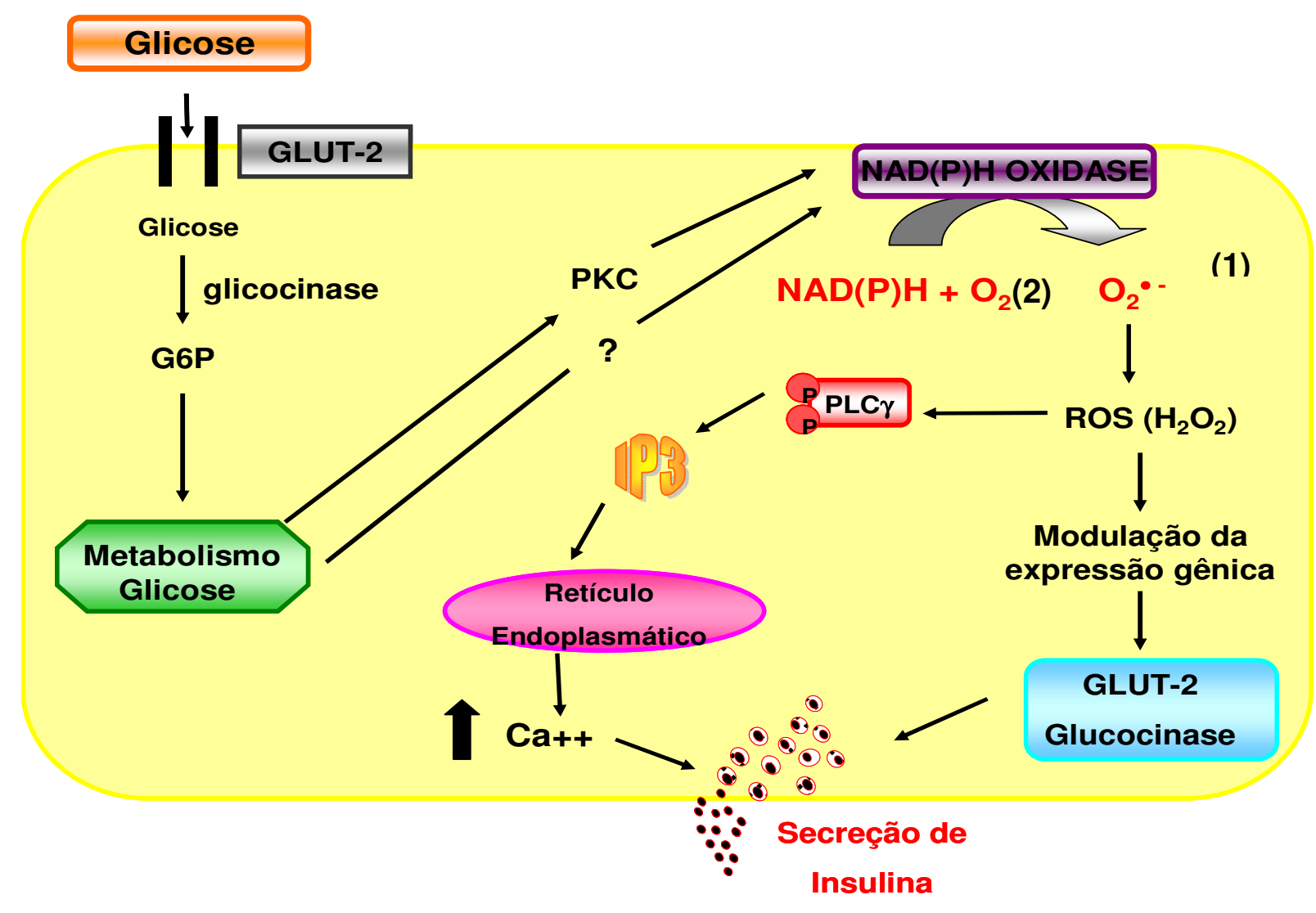

Figura 26. (1) Participação da $N A D(P) H$ oxidase na regulação da secreção de insulina através da regulação da expressão de genes essenciais para a função da célula $B$. Os aumentos da produção de espécies reativas de oxigênio agem modulando a expressão da Glicoquinase e GLUT-2 essenciais para o processo secretório e potencializando a secreção de insulina induzida pela glicose.(2) Outra hipótese de ação da enzima $\mathrm{NAD}(\mathrm{P}) \mathrm{H}$ oxidase no processo de secreção de insulina, seria através remanejamento de cálcio intracelular onde aumento da produção de superóxido leva a formação de $\mathrm{H}_{2} \mathrm{O}_{2}$, que por sua vez induz a fosforilação da PLCY que causa a ativação do $\mathrm{IP}_{3}$ provocando o aumento do cálcio intracelular. 


\section{CONCLUSÕES:}

Nossos dados permitem concluir que,

- A subunidade proteína $\mathrm{p} 47^{\mathrm{PHOX}}$ da enzima $\mathrm{NAD}(\mathrm{P}) \mathrm{H}$ oxidase, essencial para a ativação do sistema, é modulada pela glicose, palmitato e IL-1B após 1 hora de incubação.

- A atividade da $\mathrm{NAD}(\mathrm{P}) \mathrm{H}$ (medida através da produção de superóxido) é modulada pela glicose, palmitato e IL-1B.

- Ilhotas incubadas por 24 horas na presença de concentrações sub-apoptóticas de IL-1B e palmitato diminuem tanto o conteúdo protéico da $\mathrm{p} 47^{\mathrm{PHOX}}$ bem como da atividade da enzima.

- Após 24 horas de incubação a glicose continua a aumentar o conteúdo protéico da $\mathrm{p} 47^{\mathrm{PHOX}}$ bem como da atividade da enzima.

- A inibição do complexo $\mathrm{NAD}(\mathrm{P}) \mathrm{H}$ oxidase tanto pelo $\mathrm{DPI}$ (inibidor farmacológico) como pelo oligonucleotídeo antisense para $\mathrm{p} 47^{\mathrm{PHOX}}$ provocam uma redução na secreção de insulina na concentração de $16.7 \mathrm{mM}$ de glicose.

- A inibição do complexo NAD(P)H oxidase pelo DPI (inibidor farmacológico), na presença de $16.7 \mathrm{mM}$ de glicose, provoca diminuição da expressão de genes que expressam proteínas essenciais para o processo de secreção de insulina: GLUT-2 (responsável pelo transporte de glicose para o interior da célula B) e glicoquinase (enzima chave, responsável pela metabolização da glicose) sem alterar a expressão da insulina. 
- A enzima $\mathrm{NAD}(\mathrm{P}) \mathrm{H}$ oxidase participa do processo de secreção de insulina induzido pela glicose via regulação de genes essenciais para a secreção de insulina de forma concentração glicose dependente.

\section{Glicose}

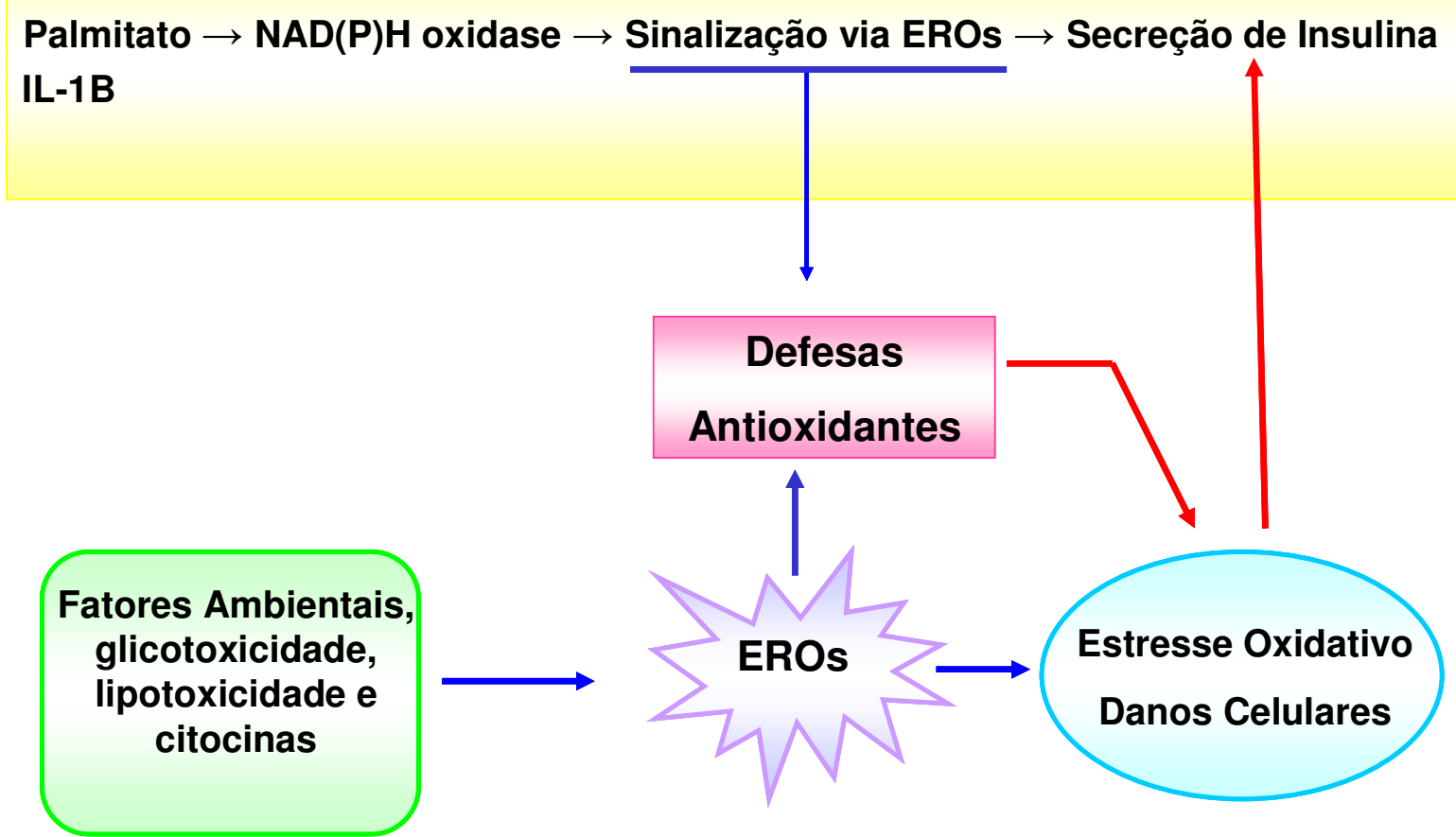

Figura 27. Esquema representando as EROs como sinalizadoras intracelulares. (1) Glicose, palmitato e IL-1 $\beta$ estimulam NAD(P)H oxidase que promove a formação das EROs, que agirão como sinalizadores intracelulares para o processo de secreção de insulina. (2) O aumento da produção de EROs aumentam a expressão e a atividade das enzimas antioxidantes a fim de preservar a fisiologia das ilhotas pancreáticas. (3) Stresse Oxidativo severo podendo resultar em danos celulares e diminuição da função celular da célula B com conseqüente diminuição da screção de insulina. 


\section{REFERÊNCIAS BIBLIOGRÁFICAS}

- ABRAMSON, S.L, GALLIN, J.I. IL-4 inhibits superoxide production by human mononuclear phagocytes. J Immunol., v. 144, p.625-630, 1990.

- BABIOR BM.The NADPH oxidase: an update. Bood, v.93, p.1464 -1476, 1999.

- BABIOR BM.; LAMBETH, J.D.; NAUSEEF, W. The neutrophil NADPH oxidase. Arch Biochem Biophysics, Arch Biochen Biophysics, v.15, p.342-344, 2002.

- BEST L, DUNLOP M, MALAISSE WJ. Phospholipid metabolism in pancreatic islets. Experientia;40:1085-91, 1984.

- BINDOKAS VP, KUZNETSOV A, SREENAN S, POLONSKY KS, ROE MW, PHILIPSON LH. Visualizing superoxide production in normal and diabetic rat islets of Langerhans. J Biol Chem. 2003 Mar 14;278(11):9796-801. Epub 2003 Jan 04 .

- BOSCHERO AC. Acoplamento excitação-secreção nas células B pancreáticas. Arq Bras Endocrinol Metab;40:149-55,1996.

- BRADFORD, M. M. A rapid and sensitive method for quantification of microgram quantities of protein utilizing the principle of protein-dye binding. Anal Biochem., v. 72, p. 248-254, 1976.

- BRODIE, AE \& RED, DJ. Reversible oxidation of glyceraldehydes 3-phosphate dehydrogenase thiols in human lung carcinoma cells by hydrogen peroxide. Biochemical and Biophysical Research Communications 148, 120-125, 1987. 
- CASSATElla ma, BAZZONI F, CALZETTI F, GUASPARRI I, ROSSI F, TRINCHIERI G. Interferon-gamma transcriptionally modulates the expression of the genes for the high affinity IgG-Fc receptor and the 47-kDa cytosolic component of NADPH oxidase in human polymorphonuclear leukocytes. J Biol Chem., v. 266, p. 22079-22082, 1991.

- CHERNY, V. V.; HENDERSON, L. M.; XU, W.; THOMAS, L. L.; DECOURSEY, T.E. Activation of NADPH oxidase-related proton and electron currents in human eosinophils by arachidonic acid. J Physiol, v. 535, p. 783-794, 2001.

- DALTON TP, SHERTZER HG, PUGA A. Regulation of gene expression by reactive oxygen. Annu Rev Pharmacology Toxicology. v. 39:67, p. 1011999. DREWS, P. K., KRAMER, C., SUSANNE, W., LANG, F., AMMON, H. P. T., DREWS, G. Interference of $\mathrm{H} 2 \mathrm{O} 2$ with stimulus-secretion coupling in mouse pancreatic $\beta$ - cells. Journal of Physiology, v. 514.2, p. 471-481, 1999.

- DROGE, W. Free radicals in the physiological control of cell function. Physiology Rev. v 82(1), p.47-95. 2002

- FUCHS A, BOUIN AP, RABILLOUD T, VIGNAIS PV. The 40-kDa component of the phagocyte NADPH oxidase (p40phox) is phosphorylated during activation in differentiated HL60 cells. Eur J Biochem, v.249, p.531-539, 1997.

- GARCIA, C.; PITHON-CURI, T. C.; DE LOURDES FIRMANO, M.; PIRES DE MELO, M.; NEWSHOLME, P.; CURI R. Effects of adrenaline on glucose and glutamine metabolism and superoxide production by rat neutrophils. Clin Sci, v. 96, p. 549-555, 1999. 
- HALLIWELL, B. Free radicals, antioxidants and human disease: Curiosity, cause or consequence. Lancet, v. 344, p. 721-724, 1994.

- HANCOCK J.T, R. DESIKAN AND S.J. NEIL. Role of reactive oxygen species in cell signaling pathways. Biochemical and Biomedical Aspects of Oxidative Modification. p. 345-350, 2001.

- HUGHES SJ, ASHCROFT SJ. Cyclic AMP, protein phosphorylation and insulin secretion. In: Flatt P, ed. Nutrient Regulation of Insulin Secretion. Portland Press: London,:271-88,1992.

- INOGUCHI, T.; LI, P.; UMEDA, F.; YU, H. Y; KAKIMOTO, M.; IMAMURA, M.; et al. High glucose level and free fatty acid stimulate reactive oxygen species production though protein kinase C-dependent activation of NADPH oxidase in culture vascular cells. Diabetes, v. 49, p. 1939-1945, 2000.

- JINGBO PI, YUSHI BAI, QIANG ZHANG, VICTORIA WONG, LISA M. FLOERING, KIEFER DANIEL,JEFFREY M. REECE, JUDE T. DEENEY, MELVIN E. ANDERSEN, BARBARA E. CORKEY,AND SHEILA COLLINS. Reactive Oxygen Species as a Signal in Glucose-Stimulated Insulin Secretion. Diabetes Vol 56, 1783-1791,2007

- JONES RD, HANCOCK JT, MORICE AH. NADPH oxidase: a universal oxygen sensor? Free Radical Biol Med., v.5, p. 416-424, 2000.

- KAmATA, H., HiRATA, H. Redox Regulation of Cellular Signalling. Cell. Signal, v.11, p.1-14, 1999. 
- KAWAMORI D, KAJIMOTO Y, KANETO H, UMAYAHARA Y, FUJITANI Y, MIYATSUKA T, WATADA H, LEIBIGER IB, YAMASAKI Y, HORI M. Oxidative stress induces nucleo-cytoplasmic translocation of pancreatic transcription factor PDX-1 through activation of c-Jun NH(2)-terminal cinase. .Diabetes, v.52 (12), p. 2896-904. 2003.

- LACY, P. E.; KOSTIANOVSKY, Y. Method for the isolation of intact islets of Langerhans from the rat pancreas. Diabetes, v. 16, p. 35-39, 1967.

- LENZEN, S., DRINKGERN, J., TIEDGE, M. Low antioxidant enzyme gene expression in pancreatic islets compared with various other mouse tissues. Free Radical Biol Med, v. 3, p. 463-466, 1996.

- LIVAK DJ, SHMITTGEN TD. Analysis of relative gene expression data using real time quantitative PCR and the 2-(Delta Delta $\mathrm{C}(\mathrm{T})$ ). Method. Methods, 25, 402-408, 2001.

- LOPES, L. R.; LAURINDO, F. R.; MANCINI-FILHO, J.; CURI, R.; SANNOMIYA, P. NADPH-oxidase activity and lipid peroxidation in neutrophils from rats fed fat-rich diets. Cell Biochem Funct; v. 17, p. 57-64, 1999.

- MAHADEV, K., WU, X., ZILBERIN, A., ZHU, L., LAWRENCE, J.T.R. Hydrogen Peroxide Generated during Cellular Insulin Stimulation Is Integral to Activation of Distal Insulin Signalling Cascade in 3TE-LI Adipocytes. The Journal of Biological Chemistry. v. 276, n 52, p. 48662-48669, 2001. 
- MATSCHINSKY FM. BANTING LECTURE 1995: a lesson in metabolic regulation inspired by the glucokinase glucose sensor paradigm. Diabetes;45:223-41,1996.

- MELLADO-GIL J M and AGUILAR-DIOSDADO M. High glucose potentiates cytokine- and streptozotocin-induced apoptosis of rat islet cells: effect on apoptosis-related genes. Journal of Endocrinology. Oct;183(1):155-62, 2004.

- MELLOUL D, MARSHAK S, CERASI E. Regulation of pdx-1 gene expression. Diabetes. v. 51, p.320-5. 2002.

- MORGAN D, OLIVEIRA-EMILIO HR, KEANE D, HIRATA AE, SANTOS DA ROCHA M, BORDIN S, CURI R, NEWSHOLME P, CARPINELLI AR. Glucose, palmitate and pro-inflammatory cytokines modulate production and activity of a phagocyte-like NADPH oxidase in rat pancreatic islets and a clonal beta cell line. Diabetologia. Feb;50(2):359-69,2007

- NAKAZAKI, M., KAKEI, M., KORIYAMA, N., TANAKA, H. Involvement of ATP sensitive $\mathrm{K}+$ channels in free radical mediated inhibition of insulin secretion in rat pancreatic $\beta$ - cell. Diabetes. v. 44, p. 878-883, 1995.

- NAKAZAKI M, KAKEI M, YAEKURA K, KORIYAMA N, MORIMITSU S, ICHINARI K, YADA T, TEI C. Diverse effects of hydrogen peroxide on cytosolic Ca2+ homeostasis in rat pancreatic beta-cells. Cell Struct Funct. v.25 (3), p.187-93. . 2000.

- NATHAN CF, MURRAY HW, WIEBE ME, RUBIN BY. Identification of interferon-gamma as the lymphokine that activates human macrophage 
oxidative metabolism and antimicrobial activity. J Exp Med., v.158, p.670-689, 1983.

- NOSE K, OHBA M. Functional activation of erg-1 (early growth gene response 1) gene by hydrogen peroxide. Biochemical journal 1196; 381-383.

- OliVEIRA, H.R., VIRLINGIA, R., CARVALHO, C.R. O, BRITTO, L.R. O, CURI, R. CARPINELLI, A R. Pancreatic B-cells express phagocyte like NAD $(P) H$ oxidase. Diabetes,2003.

- PERSAUD SJ, JONES PM, HOWELL SL. The role of protein kinase C in insulin secretion. In: Flatt P, ed. Nutrient Regulation of Insulin Secretion. Portland Press: London,:247-70,1992.

- PFAFFL MW. A new mathematical model for relative quantification in real time RT-PCR. Nucleic acids research 29 (9), 2002-7, 2001.

- PITHON-CURI, T. C.; LEVADA, A. C.; lOPES, L. R.; DOI, S. Q.; CURI, R. Glutamine plays a role in superoxide production and the expression of p47phox, p22phox and gp91phox in rat neutrophils. Clin Sci, v. 103, p. 403408, 2002.

- piro s, anello m, di Pietro C, lizZio mN, PATANè G, RABUAZZO AM, VIGNERI R, PURRELLO M, PURRELLO F. Chronic exposure to free fatty acids or high glucose induces apoptosis in rat pancreatic islets: possible role of oxidative stress. Metabolism. Oct;51(10):1340-7,2002. 
- PRENTKI M, CORKEY BE. Is the beta cell signaling molecules malonyl-CoA and cytosolic long-chain acyl-CoA implicated in multiple tissue defects of obesity and NIDDM? Diabetes;45: 273-83, 1996.

- RANDONS, J., HELleR, B., BuRKLE, A., haRTMANN, B., RODRIGUEZ, M.L., KRONCKE, K. D., BURKAT, V., KOLB, H. nitric oxide toxicity in islets cells involves poly ADP- ribose polymerase activation and concomitant NAD+ depletion. Biochemical Biophysical Research Communications. V. 199, p. 12701277, 1994.

- ROTHE, G; VALET, G. Flow Cytometric Analysis of Respiratory Burst Activity in Phagocytes with Hydroethidine and 2', 7'- Dichloroflurescin. Journal of Leukocyte Biology, v. 47, p. 440-448, 1990

- Rotrosen D, yeung CL, Leto TL, MALECH HL, KWONG CH. Cytochrome b558: the flavin-binding component of the phagocyte NADPH oxidase. Science, v. 256, p. 1459-1462, 1992.

- SCHREY MP, MONTAGUE W. Phosphatidylinositol metabolism in isolated guinea-pig islets of Langerhans. Biochemistry;216:433-41,1983.

- ShIOSE, A.; SUMIMOTO, H. Arachidonic acid and phosphorylation synergistically induce a conformational change of p47phox to activate the phagocyte NADPH oxidase. J Biol Chem, v. 275, p. 13793-13801, 2000.

- SIMON, A.R., RAI, U., FANBURG, B.L. and COCHRAN, B.H. Activation of the JAK-STAT pathway by reactive oxygen species. Am. J. Physiol. 275, p. C1640C1652, 1998. 
- SOZZANI, P.; CAMBON, C.; VITA, N.; SEGUELAS, M.H.; CAPUT, D.; FERRARA, P.,; PIPY, B. Interleukin-13 inhibits protein kinase C-triggered respiratory burst in human monocytes. Role of calcium and cyclic AMP. J Biol Chem., v. 270, p. 5084-5088, 1995.

- TURK, J., WOLF, B. A. DANIEL, M.L The role of phospholipid-derived mediators including arachidonic acid, its metabolites and inositol triphosphate and of intracellular $\mathrm{Ca}^{2+}$ in glucose-induce insulin secretion by pancreatic islets.Prog. Lipid Res, 26: 125-181, 1987.

- TANG, J., ZHANG, J. H. Mechanisms of $\left[\mathrm{Ca}^{2+}\right]$ l elevation by $\mathrm{H}_{2} \mathrm{O}_{2}$ in islets of rats. Life Sciences, 68: 475-481, 2000.

- ZAFARI, A. M.; USHIO-FUKAI, M.; AKERS, M., YIN, Q; SHAH, A.; HARRISON, D.G.; et al. Role of NADH/NADPH oxidase-derived H2O2 in angiotensin IIinduced vascular hypertrophy. Hypertension, v. 32, p. 488-495, 1998.

- ZALBA, G.; BEAUMONT, G. S. J.; FORTUNO, A.; FORTUNO, M. A.; ETAYO, J. C.; DÍEZ, J. Vascular NADH/NADPH oxidase is involved in enhanced superoxide production in spontaneously hypertensive rats. Hypertension, v. 35, p. 1055-1061, 2000.

- ZHANG, Y, MARCILLAT, O.,GICLIVI C., ERNSTER, L \& DAVIES, K.L. The oxidative inactivation of mitochodrial electron transport chain components ATPse. Journal of Biological Chemistry. 1630-1636, 1990. 
ANEXOS 